\title{
Prevalence and molecular characteristics of Staphylococcus aureus, including methicillin resistant strains, isolated from bulk can milk and raw milk products in pastoral communities of South-West Uganda
}

\author{
Benon B. Asiimwe ${ }^{1,2,3^{*}}$, Rossella Baldan', Alberto Trovato ${ }^{1}$ and Daniela M. Cirillo ${ }^{1,2}$
}

\begin{abstract}
Background: Staphylococcus aureus strains are now regarded as zoonotic agents. In pastoral settings where human-animal interaction is intimate, multi-drug resistant microorganisms have become an emerging zoonotic issue of public health concern. The study of $S$. aureus prevalence, antimicrobial resistance and clonal lineages in humans, animals and food in African settings has great relevance, taking into consideration the high diversity of ethnicities, cultures and food habits that determine the lifestyle of the people. Little is known about milk carriage of methicillin resistant $S$. aureus strains (MRSA) and their virulence factors in Uganda. Here, we present the prevalence of MRSA in bulk can milk and raw milk products in pastoral communities of south-west Uganda. We also present PFGE profiles, spa-types, as well as frequency of enterotoxins genes.
\end{abstract}

Methods: S. aureus was identified by the coagulase test, susceptibility testing by the Kirby-Bauer disc diffusion and E-test methods and MRSA by detection of the mecA gene and SCCmec types. The presence of Panton - Valentine Leucocidin (PVL) genes and staphylococcal enterotoxins was determined by PCR, while genotyping was by PFGE and spa typing.

Results: S. aureus were isolated from 30/148 (20.3\%) milk and 11/91(12\%) sour milk samples. mecA gene carriage, hence MRSA, was detected in 23/41 (56.1\%) of the isolates, with 21 of the 23 (91.3\%) being SCCmec type $V$; while up to 30/41 (73.2\%) of the isolates were resistant to tetracycline. Only five isolates carried the PVL virulence gene, while PFGE typing revealed ten clusters (ranging from two seven isolates each) that comprised $83 \%$ of the sample, and only eight isolates with unique pulsotypes. The largest PFGE profile (E) consisted of seven isolates while t7753, t1398, and t2112 were the most common spa-types. Thirty seven of the 41 strains (90.2\%) showed at least one of the eight enterotoxin genes tested, with sem 29 (70.7\%), sei 25 (61\%) and seg 21 (51.2\%) being the most frequently observed genes.

Conclusion: This is the first study to demonstrate MRSA and enterotoxin genes in raw milk and its products in Uganda. The fact that over $90 \%$ of the isolates carried at least one gene encoding enterotoxins shows a high risk of spread of foodborne diseases through milk in this setting.

\footnotetext{
*Correspondence: basiimwe@chs.mak.ac.ug

${ }^{1}$ Emerging Bacterial Pathogens Unit, IRCCS, Via Olgettina 58, Milan, Italy

${ }^{2}$ Universita Vita-Salute San Raffaele, Via Olgettina 58, Milan, Italy

Full list of author information is available at the end of the article
} 


\section{Background}

Staphylococcus aureus strains, especially those resistant to methicillin (methicillin resistant S. aureus, MRSA) have been regarded as zoonotic agents and there is growing genuine concern about the likely transmission of MRSA between animals and humans from close interaction or from handling and/or consuming MRSA infected animal products [1-5]. In settings where humans depend on animals and their products for food and livelihood, such as in pastoral Africa, contact is intimate and multi-drug resistant microorganisms have become an emerging veterinary and zoonotic issue of public health concern [6-8]. Additionally, S. aureus is known to be the third most reported cause of food-borne diseases in the world [4], culpable for production of staphylococcal enterotoxins that cause food poisoning. Moreover, contaminated milk and milk products have frequently been implicated in staphylococcal food poisoning in different industrialized countries [9]. The study of S. aureus prevalence, antimicrobial resistance and clonal lineages in humans, animals and food in African settings has great relevance, taking into consideration the high diversity of ethnicities, cultures and food habits that determine the lifestyle of the people.

The treatment of bacterial infections in Uganda's health and veterinary care settings is largely empirical with no laboratory confirmation to guide therapy, and antibiotics for both human and veterinary use are readily available over the counter. This continuous use and misuse of the antibiotics has resulted into a surge in multidrug microorganisms, now a growing problem on farms, in health care settings and the community [7, 10, 11]. In Uganda, pastoralist communities are vulnerable to zoonotic infections, including MRSA, not only because of the weak veterinary/public health delivery systems but also due to their cherished way of life (culture) dependent on animals and their products. There is limited data about prevalence and spread of $S$. aureus strains in rural pastoral farm environments in Uganda. Previous studies have reported on bacterial carriage of milk in peri and urban farmers in and around the capital, Kampala [7], while another reported on burden of $S$. aureus infection on dairy farms in the neighboring district of Kiboga [6]. However these studies neither assessed resistance to methicillin nor further characterized the isolates for resistance and virulence markers as well as genetic relatedness and spread of the strains in the study environments.

In Uganda, 92\% of the milk is marketed unregulated and in raw form [12]. This practice increases the risk of spread of staphylococcal food poisoning due to poor storage and transportation conditions. S. aureus is among the leading causes of foodborne bacterial intoxications worldwide $[13,14]$, with the most notable virulence factors being the heat-stable enterotoxins that cause the sporadic food-poisoning syndrome or foodborne outbreaks [15]. Staphylococcal enterotoxins (SEs) cause toxic shock-like syndromes and have also been implicated in several allergic and autoimmune diseases, in addition to food poisoning; therefore SEs function not only as potent gastrointestinal toxins but also as superantigens that stimulate non-specific T-cell proliferation [16].

The aim of the present study was to establish the prevalence and distribution of methicillin-susceptible S. aureus (MSSA) and MRSA in bulk can milk and raw milk products samples at household level. Furthermore, we tested the susceptibility of the isolates to nine drugs and analyzed the genetic relatedness of the isolates by PFGE and spa typing. Additionally, resistance and virulence genes (SCCmec and $P V L$ ) as well as frequency of genes encoding three of the classical staphylococcal enterotoxins (SEs): SEA, SEB and SEC; and five additional enterotoxins: SEG, SEH, SEI, SEL, and SEM were assayed.

\section{Methods \\ Study area}

The study was carried out in Sanga and Kanyaryeru subcounties of Kiruhura district, South Western Uganda. The area is a rangeland populated by agro-pastoralist households whose livelihoods are mainly dependent on consumption and trade of cattle and their products, and the area is part of the cattle corridor and is considered the milk basin of Uganda.

\section{Study design and sampling}

A total of 196 homesteads from the two sub-counties (100 from Kanyaryeru and 96 from Sanga) were randomly recruited and sampled. One pooled (bulk can) milk sample and a raw milk product (cow ghee (butter from milk) or sour (fermented) milk) were collected from each household on consent and when available at the time of visit, from July to August 2013. In Kanyaryeru sub-county, 81 milk samples, 60 ghee samples and 53 sour milk samples were collected; while 67milk samples, 57 ghee samples and 38 sour milk samples were collected from Sanga sub-county. In all, 148 milk samples, 117 ghee samples and 91 sour milk samples were collected for the study. Samples were inoculated into Brain-Heart Infusion (BHI) broth in $15 \mathrm{ml}$ propylene tubes and stored on ice in any case for not more than $12 \mathrm{~h}$ before transportation to the Department of Microbiology at Mbarara University of Science and Technology for culture and identification.

\section{Culture, isolation and identification}

Initial bacterial culture and isolation was done according to methods described by Cheesbrough [17], with minor 
modifications. Briefly, $50 \mu \mathrm{l}$ of culture broth was inoculated on 5\% sheep blood agar medium and incubated for $18-20 \mathrm{~h}$ at $37{ }^{\circ} \mathrm{C}$. Preliminary identification of the bacteria was carried out based on colony characteristics such as shape, size, color and hemolysis patterns. Isolated suspected of being $S$. aureus were shipped in BHI with $20 \%$ glycerol to the Emerging Bacterial Pathogens Unit (EBPU) at San Raffaele Scientific Institute in Milan, Italy, for identification and molecular characterization. At the EBPU, all isolates were sub-cultured on mannitol salt agar (Oxoid Ltd., Hampshire, England), then on blood agar (Becton Dickinson, Heidelberg, Germany), and subjected to the tube coagulase test in rabbit plasma with EDTA (Remel, KS, USA). Only isolates that passed the coagulase test were considered for further characterization. Isolates were also screened for susceptibility to eight antibacterial agents (cefoxitin, tetracycline, gentamycin, ciprofloxacin, rifampicin, erythromycin, clindamycin, Sulfamethoxale/Trimethoprim) on Mueller-Hinton agar (Oxoid Ltd., Hampshire, England) according to Kirby-Bauer disc diffusion method and two (oxacillin and vancomycin) by the E-test (Oxoid Ltd., Hampshire, England). Screen tests were performed in 0.5 McFarland according to EUCAST guidelines (http://www.eucast.org/ clinical_breakpoints/).

DNA extraction, SCCmec typing and PVL genes detection Bacterial DNA was prepared from isolated colonies suspended in $500 \mathrm{ml}$ Triton X-100 lysis buffer with $1 \%$ Triton and $50 \mathrm{mg} / \mathrm{ml}$ lysostaphin, incubated at $37{ }^{\circ} \mathrm{C}$ for $1 \mathrm{~h}$, followed by phenol-chloroform extraction. Staphylococcal Cassette Chromosome harboring mecA (SCCmec) gene multiplex PCR typing was done. This was performed using primers and protocols for SCCmec types and subtypes I, II, III, IVa, IVb, IVc, IVd, and V and the mecA gene according to Zhang et al.[18]. We also assayed for the recently described $m e c A$ homologue, mecC shown to be common in animal-derived strains, using primers and conditions as described in Paterson et al. [19]. The MRSA strain COL (SCCmec type I, mec gene complex B and ccr gene complex 1) was also used as positive control. We further used control strains for SCCmec II (Mu50), III (ANS46), IVa (USA300-FPR3757), IVb (strain from Ospedale San Raffale (OSR) MRSA 864), IVc (strain from OSR collection, MRSA 111), IVd (strain from OSR collection, MRSA 1040) and V (S0385). Unfortunately a control for SCCmec type IV from subtype "e" to subtype "k" was not available to us. Additionally, amplification of the Panton - Valentine Leucocidin $(P V L)$ toxin genes, lukS-PV and $l u k F-P V$, was performed using the $S$. aureus strain ATCC49775 as positive control, and primers and protocols as described by Lina et al. [20].

\section{Pulsed-field gel electrophoresis (PFGE) and spa typing}

All isolates were subjected to molecular epidemiological analysis by PFGE after SmaI digestion using the CHEF Genomic DNA Plug kit (Bio-Rad) according to a standardized protocol [21]. PFGE was run using a CHEF DRIII system (Bio-Rad). The InfoQuest FP (v5) software (Bio-Rad Laboratories) was used to analyze PFGE profiles, according to interpretation criteria described by Tenover et al. [22]. Clustering analysis was achieved using Dice similarity coefficients and the unweighted pair group method with averages (UPGMA) at 1.5\% optimization and $1.5 \%$ position tolerance. Additionally, isolates were typed based on sequencing of the hypervariable region of the $S$. aureus protein A gene (spa); spa types were assigned MLST sequence types (ST) inferred on the Ridom spaServer (http://spaserver.ridom.de) curated by the SeqNet.org initiative [23].

\section{Staphylococcal enterotoxins genes detection by PCR}

DNA amplification was performed using the following conditions: initial denaturation for $15 \mathrm{~min}$ at $95^{\circ} \mathrm{C}$ followed by 35 cycles of denaturation $\left(94^{\circ} \mathrm{C}\right.$ for $\left.1 \mathrm{~min}\right)$, annealing, and extension $\left(72^{\circ} \mathrm{C}\right.$ for $\left.1 \mathrm{~min}\right)$, and a final extension step $\left(72^{\circ} \mathrm{C}\right.$ for $\left.10 \mathrm{~min}\right)$ after the completion of the cycles. The primer sequences, annealing temperatures and expected amplicon sizes are as described in Jarraud et al. [24] and Diep et al. [25]. DNA extracted from the standard strains S. aureus Mu50 [26] was used as positive control for enterotoxins SEA, SEC, SEG, SEI, SEL and SEM; while DNA from S.aureus COL [27] controlled for enterotoxins SEB and SEH.

\section{Results}

Prevalence of MSSA and MRSA

Of the samples that were collected, only 56 of 148 milk samples, 25 of 91 sour milk samples and one of 117 cow ghee samples gave growth that was suspected to be $S$. aureus based on colony characteristics such as size, shape, color and hemolysis patterns on blood agar. These samples were then sub-cultured and re-identified at the EBPU and only 30 of 56 isolates from milk and 11 of the 25 isolates from sour milk were coagulase positive, while the single isolate from ghee failed the coagulase test. The prevalence of $S$. aureus in the bulk can milk thus was 30/148 (20.3\%) while that in the sour milk was $11 / 91$ (12.1\%). Isolation of S. aureus was unevenly distributed between the two study areas, with 25 isolates from Kanyaryeru and 16 isolates from Sanga.

\section{Drug susceptibility, mecA, SCCmec and PVL gene}

Of the 356 samples cultured (148 fresh milk, 91 sour milk and 117 ghee), S. aureus was isolated from 30 (53.6\%) of milk, 11 (44\%) of sour milk and none were recovered from ghee samples. Carriage of the mecA gene 
(hence MRSA) in this study, identified as part of the Staphylococcal Cassette Chromosome harboring mecA (SCCmec) after multiplex PCR, was 50\% (15/30) and $72.7 \%(8 / 11)$ of the milk and sour milk derived isolates respectively. Overall, only five isolates $(5 / 41,12.2 \%)$ carried the $P V L$ virulence gene. A majority of the isolates with the $m e c A$ gene $(21 / 23 ; 91.3 \%)$ were type V. Nosne of the isolates tested carried the mecA homologue, $m e c C$. When screened with cefoxitin, only two of the 23 isolates carrying the mecA gene had zones of inhibition $\leq 22 \mathrm{~mm}$, hence a discrepancy between the phenotypic and genotypic results. The two isolates resistant to cefoxitin also had MICs of oxacillin above the breakpoint of $2 \mathrm{mg} / \mathrm{L}$, hence resistant. There was a high resistance to tetracycline (73.2\%), while all isolates were fully susceptible to ciprofloxacin and vancomycin. The susceptibility pattern of the other drugs tested is shown in Table 1.

\section{PFGE restriction profiles and spa types}

There were ten clusters (ranging from two to seven isolates each) that comprised $83 \%$ of the sample, while only eight isolates had unique pulsotypes (Table 2). The largest PFGE profile (E) consisted of seven isolates, all with unknown spa types. The most common spa types were t7753 and t1398 (four isolates each), while others were t2112 (three isolates), t3992 and t127 (two isolates each). The PFGE profiles and spa types of the isolates are shown in Table 2.

\section{Frequency of staphylococcal enterotoxins (SEs)}

Results for the detection of eight genes encoding the enterotoxins SEA, SEB, SEC, SEG, SEH, SEI, SEL, and SEM are shown in Table 2, in which 37 of 41 strains (90.2\%) were positive for at least one enterotoxin gene. The distribution of enterotoxin genes in MRSA and MSSA strains as well as in milk and sour milk samples was unequal, with MSSA and milk-derived isolates showing more strains with multiple enterotoxins. There were 17/30 (56.7\%) milk-derived strains carrying at least three enterotoxins genes while only $3 / 11(27.3 \%)$ of isolates from sour milk carried more than three. Among the genes that code for three of the classic enterotoxins assayed (SEA-SEC), sec was the most frequent with 10 isolates $(24.4 \%)$; while in the other enterotoxins, sem (29/41; 70.7\%), sei $(25 / 41 ; 61 \%)$ and seg $(21 / 41 ; 51.2 \%)$ were the most frequently observed genes. The proportion of all the other enterotoxins can be seen in Table 3 . Only four isolates (two from raw milk and two from sour milk) did not carry any of the eight enterotoxin genes that were assayed.

\section{Discussion}

Pastoralists within Uganda's cattle corridor are afflicted by a variety of ecosystem-based human/livestock health problems, especially those zoonotic in nature, with potential to spill over to neighboring communities and affecting the tourism industry. Unfortunately, not much has been done to estimate the burden of many such potentially zoonotic infections in these marginalized communities. S. aureus, including MRSA, has recently been found to be a zoonotic problem in different settings [2, 3, 28]. We set out to study the prevalence of methicillin resistance, virulence factors, and genetic relatedness of $S$. aureus strains isolated from bulk can milk and milk products from pastoral households around L. Mburo national Park.

S. aureus was isolated in $20.3 \%$ of bulk can milk samples and $12.1 \%$ of sour milk samples. Generally, there is a paucity of data on S. aureus from milk and raw milk products in the region. In urban and peri-urban Kampala, a recent study of 97 milk samples yielded 85 pure cultures, but only 1 of 58 (2\%) Gram-positive bacteria was identified as S. aureus while 20 of 58 (34\%) were coagulase negative Staphylococci [7]. Another study carried out in dairy farms in rural Kiboga (another cattle corridor district) in Uganda, however, found that the most prevalent bacterial pathogens associated with sub-clinical mastitis in dairy cattle were Staphylococci such as Coagulase negative Staphylococci and S. aureus in 64.42 and $16.56 \%$ of the cases respectively [6], comparable to our finding of $19.6 \%$ S. aureus in fresh bulk can milk samples in the current study. These findings support the expectation that $S$. aureus from infected udders may contaminate bulk milk and, subsequently, raw milk products as has been observed elsewhere [29].

SCCmec PCR showed that 23/41 (56.1\%) of the isolates carried the mecA gene implicated in resistance

Table 1 Drug susceptibility pattern of the study isolates to eight of the 10 antimicrobial agents tested

\begin{tabular}{|c|c|c|c|c|c|c|c|c|c|c|c|c|c|c|c|c|c|}
\hline \multirow[t]{3}{*}{ Source } & \multirow[t]{3}{*}{ S. aureus } & \multicolumn{16}{|c|}{ Drug susceptibility pattern } \\
\hline & & \multicolumn{2}{|l|}{$\mathrm{TE}$} & \multicolumn{2}{|c|}{$\mathrm{RD}$} & \multicolumn{2}{|c|}{ SXT } & \multicolumn{2}{|c|}{$\mathrm{CIP}$} & \multicolumn{2}{|l|}{ E } & \multicolumn{2}{|c|}{$\mathrm{CN}$} & \multicolumn{2}{|c|}{ DA } & \multicolumn{2}{|c|}{ VA } \\
\hline & & $\mathrm{R}$ & $\mathrm{S}$ & $\mathrm{R}$ & $S$ & $\mathrm{R}$ & S & $\mathrm{R}$ & $S$ & $\mathrm{R}$ & $S$ & $\mathrm{R}$ & $S$ & $\mathrm{R}$ & $S$ & $\mathrm{R}$ & $S$ \\
\hline Milk & 30 & 20 & 10 & 1 & 29 & 1 & 29 & 0 & 30 & 1 & 29 & 1 & 29 & 2 & 28 & 0 & 30 \\
\hline Sour milk & 11 & 10 & 1 & 0 & 11 & 1 & 10 & 0 & 11 & 0 & 11 & 0 & 11 & 0 & 11 & 0 & 11 \\
\hline Total & 41 & 30 & 11 & 1 & 40 & 2 & 39 & 0 & 41 & 1 & 40 & 1 & 40 & 2 & 39 & 0 & 41 \\
\hline
\end{tabular}

$T E$ tetracycline, $R D$ rifampicin, $S X T$ trimethoprim-sulphamethoxale, $C I P$ ciprofloxacin, $E$ erythromycin, $C N$ gentamycin, $D A$ clindamycin, $V A$ vancomycin 
Table 2 Molecular characteristics of the 41 isolates of S. aureus in the study

\begin{tabular}{|c|c|c|c|c|c|c|}
\hline Isolate ID & Pulsotype & spa type & MLST & $P V L$ & mecA & sccmec \\
\hline T130 m & $\mathrm{A} 1$ & t1398 & & - & - & - \\
\hline T132 m & A1 & $\mathrm{t} 2112$ & & - & + & V \\
\hline T111 m & A2 & t380 & & + & - & - \\
\hline T119 m & A3 & t7753 & & - & - & - \\
\hline T147y & A4 & $\mathrm{t} 2112$ & & - & + & V \\
\hline T067 m & B1 & $\mathrm{t} 127$ & ST-1 & - & + & V \\
\hline T089y & B1 & $\mathrm{t} 127$ & ST-1 & - & + & V \\
\hline T120y & C1 & $\mathrm{t} 1236$ & ST-97 & - & - & - \\
\hline T139 m & $\mathrm{C} 1$ & t7753 & & - & - & - \\
\hline T115 m & $C 2$ & $\mathrm{t} 10103$ & & - & - & - \\
\hline T089 m & C3 & $\mathrm{t} 7753$ & & - & - & - \\
\hline T099y & C4 & t14299 & & - & + & V \\
\hline T041y & D1 & Unknown & & - & + & V \\
\hline T042 m & D2 & Unknown & & - & - & - \\
\hline T127 m & D3 & Unknown & & - & + & V \\
\hline T031 m & E1 & Unknown & & - & + & V \\
\hline T117 m & E2 & Unknown & & - & - & - \\
\hline T136 m & E3 & Unknown & & - & + & V \\
\hline T105 m & E4 & Unknown & & - & - & - \\
\hline T143 m & E4 & Unknown & & - & - & - \\
\hline T094 m & E5 & Unknown & & - & - & - \\
\hline T148 m & E5 & Unknown & & - & + & V \\
\hline T019 m & F1 & t645 & ST-121 & + & + & V \\
\hline T057 m & $\mathrm{F} 1$ & Unknown & & - & + & V \\
\hline T103 m & G1 & t1398 & & - & + & V \\
\hline T145 m & G1 & t1398 & & - & + & V \\
\hline T030 m & G2 & t1398 & & - & - & - \\
\hline T098y & $\mathrm{H} 1$ & t186 & ST-88 & - & - & - \\
\hline T120 m & $\mathrm{H} 2$ & Unknown & & - & + & V \\
\hline T037 m & 11 & Unknown & & - & + & V \\
\hline T067y & 12 & Unknown & & - & + & V \\
\hline T059y & L1 & t2112 & & + & + & V \\
\hline T091 m & L2 & t1236 & ST-97 & - & - & - \\
\hline T032 m & Unique & Unknown & & + & + & IV \\
\hline T037y & Unique & Unknown & & - & + & V \\
\hline T049 m & Unique & Unknown & & - & - & - \\
\hline T055 m & Unique & Unknown & & - & - & - \\
\hline T056 m & Unique & t3992 & ST-97 & - & + & V \\
\hline T055y & Unique & t3992 & ST-97 & - & - & - \\
\hline T144 m & Unique & t7753 & & - & + & IVC \\
\hline T157y & Unique & t3772 & & + & + & V \\
\hline
\end{tabular}

$\mathrm{PVL}=$ presence (+) or absence (-) of the $P V L$ gene; mecA = presence (+) or absence $(-)$ of the mecA gene; $\mathrm{SCCmec}=\mathrm{SCCmec}-\mathrm{typ}$ es according to Zhang et al. [18]
Table 3 Genotypic profile of S. aureus strains, according to sea, seb, sec, seg, seh, sei, sel, and sem genes

\begin{tabular}{llll}
\hline Genotypic profile & $\begin{array}{l}\text { Raw milk } \\
(n=30)\end{array}$ & $\begin{array}{l}\text { Sour milk } \\
(n=11)\end{array}$ & Total (\%) \\
\hline sea & 1 & 1 & $2(4.9)$ \\
seb & 4 & 2 & $6(14.6)$ \\
Sec & 7 & 3 & $10(24.4)$ \\
Seg & 16 & 5 & $21(51.2)$ \\
She & 13 & 2 & $15(36.6)$ \\
Sei & 17 & 8 & $25(61)$ \\
Sel & 8 & 2 & $10(24.4)$ \\
Sem & 21 & 8 & $29(70.7)$ \\
sea + seb + sec & 3 & 0 & $3(7.3)$ \\
seg + seh + sei + sel + sem & 9 & 1 & $10(24.4)$ \\
At least 1 SE gene & 28 & 9 & $37(90.2)$ \\
No SE gene detected & 2 & 2 & $4(9.8)$ \\
\hline
\end{tabular}

to methicillin. Elsewhere in Africa, however, low level MRSA carriage in raw milk has been reported in Algeria where only two of five isolates were screened by the disc diffusion test, but there was no testing for the mecA gene [30]. In the current study, only two isolates had zones of clearance less than $22 \mathrm{~mm}$ around cefoxitin discs as recommended by EUCAST, to be considered MRSA. The two isolates also had MIC of $>2 \mathrm{mg} / \mathrm{L}$ on oxacillin strips, hence resistant. The discrepancy between the phenotypic and genotypic results seen in this study may be due to a lack of expression of mecA. Routine oxacillin tests often fail to detect very heterogeneous MRSA populations, which consequently are considered methicillin-susceptible $S$. aureus (MSSA) because of their usual susceptibility to most non- $\beta$-lactam antistaphylococcal antibiotics. Therefore, several parameters have been recommended to improve results and these include increasing the inoculum, growth at a low temperature, an oxacillin screen test with $\mathrm{NaCl}$, or protracted incubation [31]. More recent methods for detection of MRSA include the oxacillin E-test (AB BIODISK, Solna, Sweden) for determination of MICs, and the automated Vitek 2 system (bioMe'rieux, La Balme les Grottes, France). Phenotypic results will therefore vary between laboratories depending on the system used. Detection of the mecA gene, therefore, would be a good way of standardizing identification of MRSA across laboratories. The results are similar to those in another study comparing methods for the detection of MRSA on isolates from foods of animal origin in Italy by Corrente et al. [31]. In that study, none of the six MRSA strains identified by mecA PCR were detected by the cefoxitin test (sensitivity of $0 \%$ ), and they concluded that analysis for MRSA in isolates from food of animal origin is better done with the mecA gene-specific PCR rather than conventional phenotypic assays [31]. More studies in 
human derived strains also render support to low sensitivity of the cefoxitin test. For example, a recent study of low level methicillin resistance in mecA positive $S$. aureus strains showed zones of clearance of $28 \mathrm{~mm}$ diameter by cefoxitin testing [32]. In the current study, 17 of the 23 $m e c A$ positive strains also had zones of clearance of $\leq 28 \mathrm{~mm}$ (Table 1). The observation of a high proportion of MRSA in the study sample is very worrisome because studies have shown that MRSA readily jumps from animals to exposed veterinarians, farm works and other farm animals $[2,5,28]$. This, to the best of our knowledge, is the first report of MRSA isolated from milk and raw milk products under communally grazing pastoral households in Uganda. In this setting where animal - human interaction is intimate due to the pastoralists' cherished way of life, it creates an urgent public health concern.

Genotype analysis was done by SCCmec typing and PFGE. Of the 23 mecA positive (MRSA) isolates, 21 harboured the SCCmec type V. The other SCCmec types found can be seen in Table 2. It has recently been noted that community-associated MRSA (CA-MRSA) isolates, which carry SCCmec type IV or V, are now prevalent and exceed methicillin-susceptible S. aureus (MSSA) in skin and soft tissue infections, and such isolates were reported to cause severe, often necrotizing, soft tissue infections and pneumonia [33, 34]. Their presence in milk creates risk of spread of these genotypes in the communities. Additionally, assaying for the virulence marker $P V L$ showed that only four isolates were positive for this gene. A previous study of $50 \mathrm{~S}$. aureus isolates from 14 dairy cow herds in Italy identified the $P V L$ gene in more than $50 \%$ of the isolates [35], while another in Brazil reported that none of the 84 milk derived $S$. aureus isolates harbored the $P V L$ gene [36].

According to criteria proposed by Tenover et al., [22], strains that differ by three bands or fewer by PFGE are likely to be closely related. The authors emphasized that these criteria apply to epidemiologically related isolates. By these criteria, isolates in the current study group into ten clusters of two to seven isolates each, and only eight unique strains. Since these were not outbreak strains, spa typing was used to determine the clonal lieneages of the isolates. The most common lineages were t7753 and t1398 with four isolates each. In all, there were 13 different lineages, but most of the isolates $(17 / 41,41.5 \%)$ could not be assigned to any lineage and were designated as unknown (Table 2). Only one lineage in the current study, t645, had been isolated from one mastitic cow and four milkmen in peri-urban Kampala [7]. The most common spa types associated with clone ST398 (t011, t034, t108, t567, t571, t588, t753, t753, t779, t898, t899, t943, t1184, t1197, t1254, t1255, t1451, t1456, t1457, t2123, t2287, t2329, t2330, t2383, t2582, t2748, t2971, t2974, t3013, t3014, t3053, t3146, or t3208) according to the recent work [37] were not found among our isolates. However, we detected other spa types that have been reported to be associated with LA-MRSA strains other than ST398 (Table 2).

This, to the best of our knowledge, is the first report of SEs in milk from Uganda. While literature elsewhere suggests that the classical SEA is the most frequently observed in enterotoxigenic strains of S. aureus [38], it was found in only two (4.9\%) of the strains in the current study. This is probably because of the fact that different foods and strains carry different enterotoxins, as observed elsewhere [39]. On the other hand, the more recently discovered seg gene was observed in 21 (51.2\%) of 41 isolates, and in $85.7 \%$ of the cases, it was associated with sei, which was present in $25(61 \%)$ of the isolates, similar to reports in other studies in Brazil [40] and France [41]. These genes are known to be frequently found together because they are within the same cluster, in a $3.2 \mathrm{~kb}$ DNA fragment as reported elsewhere [42]. In East Africa, most milk is produced by small holders and the bulk of it (86\% in Kenya and 92\% in Uganda) is traded through unregulated channels as unpasteurized milk or milk products [12]. Raw and sour milk are consumed in these settings for such beliefs as enhanced nutritional quality and better taste. The fact that over $90 \%$ of the isolates in the current study carried at least one gene encoding for enterotoxins shows a high risk of spread of foodborne diseases in this setting, with milk as a vehicle for dispersion. There is a need for farmer education and health promotion messages in the communities about the need for pasteurization of milk as this will kill S. aureus, therefore reducing enterotoxin production.

\section{Conclusion}

Our results show a high proportion of MRSA in raw milk and its products in the cattle corridor of Uganda, threatening treatment options for S. aureus in the near future in this setting, especially if the strains cross the species barrier into humans. Isolates carrying SCCmec type $\mathrm{V}$ are wide spread in this setting. The fact that over $90 \%$ of the isolates in the current study carried at least one gene encoding for enterotoxins shows a high risk of spread of foodborne diseases. A limitation of this study is that the enterotoxin genes were not studied for expression, therefore we cannot confirm their significance in cases of food poisoning. Additionally, the initial processing and culture technique for the samples was not good enough whereby only 82 of the 356 samples yielded suspected S. aureus. 


\section{Acknowledgments}

The authors wish to thank the households that participated in the study. We also thank Dr. F. Agnoletti and Dr. I. Drigo from the Istituto Zooprofilattico Sperimentale delle Venezie, Italy, who kindly provided us with control strain LGA251.

\section{Funding}

BBA was supported by a Marie Curie Fellowship (MARIE CURIE - COFUND project No. 267264)

\section{Availability of data and materials}

All data supporting the conclusions of this article are included within the article.

\section{Authors' contributions}

BBA collected samples and data, participated in performing all the laboratory analyses and wrote the first draft of the manuscript; RB participated in analyzing and interpreting PFGE data and critical revision of the manuscript; AT participated in performing PFGE; DMC supervised the study and critically revised the manuscript. All authors read and approved the final manuscript.

\section{Competing interests}

The authors declare that they have no competing interests.

\section{Consent for publication}

Not applicable.

\section{Ethics approval and consent to participate}

The study was approved by Institutional Review Board of Makerere University School of Medicine Research and Ethics Committee and the Uganda National Council for Science and Technology (UNCST). The study objective was explained in the local language and written informed consent obtained from household heads before fresh milk or milk products samples were collected.

\section{Publisher's Note}

Springer Nature remains neutral with regard to jurisdictional claims in published maps and institutional affiliations.

\section{Author details}

${ }^{1}$ Emerging Bacterial Pathogens Unit, IRCCS, Via Olgettina 58, Milan, Italy. ${ }^{2}$ Universita Vita-Salute San Raffaele, Via Olgettina 58, Milan, Italy. ${ }^{3}$ Department of Medical Microbiology, Makerere University College of Health Sciences, P O Box 7072, Kampala, Uganda.

\section{Received: 14 February 2017 Accepted: 5 June 2017}

\section{Published online: 13 June 2017}

\section{References}

1. van Loo IH, Diederen BM, Savelkoul PH, Woudenberg JH, Roosendaal R, et al. Methicillin-resistant Staphylococcus aureus in meat products, the Netherlands. Emerg Infect Dis. 2007;13:1753-5.

2. Juhasz-Kaszanyitzky E, Janosi S, Somogyi P, Dan A, van der Graaf-van Bloois $L$, et al. MRSA transmission between cows and humans. Emerg Infect Dis. 2007:13:630-2

3. Garcia-Alvarez L, Holden MT, Lindsay $H$, Webb CR, Brown DF, et al. Meticillin-resistant Staphylococcus aureus with a novel mecA homologue in human and bovine populations in the UK and Denmark: a descriptive study. Lancet Infect Dis. 2011:11:595-603.

4. Normanno G, Corrente M, La Salandra G, Dambrosio A, Quaglia NC, et al. Methicillin-resistant Staphylococcus aureus (MRSA) in foods of animal origin product in Italy. Int J Food Microbiol. 2007;117:219-22.

5. Lee JH. Methicillin (Oxacillin)-resistant Staphylococcus aureus strains isolated from major food animals and their potential transmission to humans. Appl Environ Microbiol. 2003;69:6489-94.

6. Kasozi Kl, Tingiira JB, Vudriko P. High prevalence of subclinical mastitis and multidrug resistant Staphylococcus aureus are a threat to dairy cattle production in Kiboga District (Uganda). Open J Vet Med. 2014:4:35-43.

7. Kateete DP, Kabugo U, Baluku H, Nyakarahuka L, Kyobe S, et al. Prevalence and antimicrobial susceptibility patterns of bacteria from milkmen and cows with clinical mastitis in and around Kampala, Uganda. PLoS One. 2013;8:e63413.
8. Kamau NPM, Dolci S, Jans C, Wangoh J, Lacroix C, et al. Phenotypic and genotypic antibiotic resistance patterns of Staphylococcus aureus from raw and spontaneously fermented camel milk. Eur J Nutr Food Safety. 2013;3:87-98.

9. De Buyser ML, Dufour B, Maire M, Lafarge V. Implication of milk and milk products in food-borne diseases in France and in different industrialised countries. Int J Food Microbiol. 2001;67:1-17.

10. Kateete DP, Namazzi S, Okee M, Okeng A, Baluku H, et al. High prevalence of methicillin resistant Staphylococcus aureus in the surgical units of Mulago hospital in Kampala, Uganda. BMC Res Notes. 2011;4:326.

11. Seni J, Bwanga F, Najjuka CF, Makobore P, Okee M, et al. Molecular characterization of Staphylococcus aureus from patients with surgical site infections at Mulago Hospital in Kampala, Uganda. PLoS One. 2013;8:e66153.

12. Grace D, Omore A, Randolph T, Kang'ethe E, Nasinyama GW, et al. Risk assessment for Escherichia coli 0157:H7 in marketed unpasteurized milk in selected east African countries. J Food Prot. 2008:71:257-63.

13. Genigeorgis CA. Present state of knowledge on staphylococcal intoxication. Int J Food Microbiol. 1989:9:327-60.

14. Tauxe RV. Emerging foodborne pathogens. Int J Food Microbiol. 2002; 78:31-41

15. Kerouanton A, Hennekinne JA, Letertre C, Petit L, Chesneau O, et al. Characterization of Staphylococcus aureus strains associated with food poisoning outbreaks in France. Int J Food Microbiol. 2007;115:369-75.

16. Balaban N, Rasooly A. Staphylococcal enterotoxins. Int J Food Microbiol. 2000;61:1-10.

17. Cheesbrough M District laboratory practice in tropical countries, part 2. 2nd edition.: 62-70, 132-143, 157-234. 2005.

18. Zhang K, McClure JA, Elsayed S, Louie T, Conly JM. Novel multiplex PCR assay for characterization and concomitant subtyping of staphylococcal cassette chromosome mec types I to $\mathrm{V}$ in methicillin-resistant Staphylococcus aureus. J Clin Microbiol. 2005;43:5026-33.

19. Paterson GK, Larsen AR, Robb A, Edwards GE, Pennycott TW, et al. The newly described mecA homologue, mecALGA251, is present in methicillinresistant Staphylococcus aureus isolates from a diverse range of host species. J Antimicrob Chemother. 2012;67:2809-13.

20. Lina G, Piemont $Y$, Godail-Gamot F, Bes M, Peter MO, et al. Involvement of Panton-Valentine leukocidin-producing Staphylococcus aureus in primary skin infections and pneumonia. Clin Infect Dis. 1999;29:1128-32.

21. Baldan R, Tassan Din C, Semeraro G, Costa C, Cichero P, et al. Severe community-onset infections in healthy individuals caused by community-acquired MRSA in an Italian teaching hospital, 2006-2008. J Hosp Infect. 2009;72:271-3.

22. Tenover FC, Arbeit RD, Goering RV, Mickelsen PA, Murray BE, et al. Interpreting chromosomal DNA restriction patterns produced by pulsed-field gel electrophoresis: criteria for bacterial strain typing. J Clin Microbiol. 1995:33:2233-9.

23. Mellmann A, Friedrich AW, Rosenkotter N, Rothganger J, Karch $\mathrm{H}$, et al. Automated DNA sequence-based early warning system for the detection of methicillin-resistant Staphylococcus aureus outbreaks. PLoS Med. 2006;3:e33.

24. Jarraud S, Mougel C, Thioulouse J, Lina G, Meugnier H, et al. Relationships between Staphylococcus aureus genetic background, virulence factors, agr groups (alleles), and human disease. Infect Immun. 2002;70:631-41.

25. Diep BA, Carleton HA, Chang RF, Sensabaugh GF, Perdreau-Remington F. Roles of 34 virulence genes in the evolution of hospital- and communityassociated strains of methicillin-resistant Staphylococcus aureus. J Infect Dis. 2006;193:1495-503.

26. Kuroda M, Ohta T, Uchiyama I, Baba T, Yuzawa H, et al. Whole genome sequencing of meticillin-resistant Staphylococcus aureus. Lancet. 2001;357:1225-40.

27. Gill SR, Fouts DE, Archer GL, Mongodin EF, Deboy RT, et al. Insights on evolution of virulence and resistance from the complete genome analysis of an early methicillin-resistant Staphylococcus aureus strain and a biofilmproducing methicillin-resistant Staphylococcus epidermidis strain. J Bacteriol. 2005:187:2426-38

28. Sakwinska O, Giddey M, Moreillon M, Morisset D, Waldvogel A, et al. Staphylococcus aureus Host range and human-bovine host shift. Appl Environ Microbiol. 2011;77:5908-15

29. Jorgensen HJ, Mork T, Caugant DA, Kearns A, Rorvik LM. Genetic variation among Staphylococcus aureus strains from Norwegian bulk milk. Appl Environ Microbiol. 2005;71:8352-61.

30. Chaalal W, Aggad H, Saidi N, Kihal M. Prevalence and antimicrobial resistance of Methicillin-resistant Staphylococcus aureus isolated from raw meat and bovine milk in Algeria. Adv Environ Biol. 2014;8:1-5. 
31. Corrente M, Normanno G, Martella V, Bellacicco AL, Quaglia NC, et al. Comparison of methods for the detection of methicillin resistance in Staphylococcus aureus isolates from food products. Lett Appl Microbiol. 2007:45:535-9.

32. Witte W, Pasemann B, Cuny C. Detection of low-level oxacillin resistance in mecA-positive Staphylococcus aureus. Clin Microbiol Infect. 2007;13:408-12.

33. Bhattacharya D, Carleton H, Tsai CJ, Baron EJ, Perdreau-Remington F. Differences in clinical and molecular characteristics of skin and soft tissue methicillin-resistant Staphylococcus aureus isolates between two hospitals in northern California. J Clin Microbiol. 2007;45:1798-803.

34. Ganga R, Riederer K, Sharma M, Fakih MG, Johnson LB, et al. Role of SCCmec type in outcome of Staphylococcus aureus bacteremia in a single medical center. J Clin Microbiol. 2009;47:590-5.

35. Zecconi A, Cesaris L, Liandris E, Dapra V, Piccinini R. Role of several Staphylococcus aureus virulence factors on the inflammatory response in bovine mammary gland. Microb Pathog. 2006;40:177-83.

36. Aires-de-Sousa M, Parente CE, Vieira-da-Motta O, Bonna IC, Silva DA, et al. Characterization of Staphylococcus aureus isolates from buffalo, bovine, ovine, and caprine milk samples collected in Rio de Janeiro state, Brazil. Appl Environ Microbiol. 2007;73:3845-9.

37. Hetem DJ, Bootsma MC, Troelstra A, Bonten MJ. Transmissibility of livestockassociated methicillin-resistant Staphylococcus aureus. Emerg Infect Dis. 2013;19:1797-802.

38. Normanno G, Firinu A, Virgilio S, Mula G, Dambrosio A, et al Coagulase-positive Staphylococci and Staphylococcus aureus in food products marketed in Italy. Int J Food Microbiol. 2005:98:73-9.

39. Mathieu AM, Isigidi BK, Devriese LA, Godard C, Vanhoof R. Characterization of Staphylococcus aureus and salmonella spp. strains isolated from bovine meat in Zaire. Int J Food Microbiol. 1991;14:119-25.

40. Rall VL, Vieira FP, Rall R, Vieitis RL, Fernandes A Jr, et al. PCR detection of staphylococcal enterotoxin genes in Staphylococcus aureus strains isolated from raw and pasteurized milk. Vet Microbiol. 2008;132:408-13.

41. Rosec JP, Gigaud O. Staphylococcal enterotoxin genes of classical and new types detected by PCR in France. Int J Food Microbiol. 2002;77:61-70.

42. Jarraud S, Peyrat MA, Lim A, Tristan A, Bes M, et al. Egc, a highly prevalent operon of enterotoxin gene, forms a putative nursery of superantigens in Staphylococcus aureus. J Immunol. 2001;166:669-77.

\section{Submit your next manuscript to BioMed Central and we will help you at every step:}

- We accept pre-submission inquiries

- Our selector tool helps you to find the most relevant journal

- We provide round the clock customer support

- Convenient online submission

- Thorough peer review

- Inclusion in PubMed and all major indexing services

- Maximum visibility for your research

Submit your manuscript at www.biomedcentral.com/submit 